\title{
ESCALA DE SATISFAÇÃO COM A EXPERIÊNCIA ACADÊMICA DOS ESTUDANTES DO IFMG - CAMPUS PIUMHI ${ }^{1}$
}

\author{
Higor Rodrigues Silva Costa \\ Pedro Henrique da Costa \\ Tales Junio Costa Chaves \\ Denilson Junio Marques Soares
}

\begin{abstract}
RESUMO
Este artigo tem como objetivo analisar o grau de satisfação dos estudantes do curso de Bacharelado em Engenharia Civil do Instituto Federal de Minas Gerais (IFMG) - Campus Avançado Piumhi. O estudo, de caráter analítico-descritivo, foi desenvolvido a partir de dados qualitativos, levantados através de um questionário composto por 20 perguntas selecionadas da Escala de Satisfação com a Experiência Acadêmica (ESEA), sendo 7 referentes ao Campus, 6 ao curso de Engenharia Civil e 7 às oportunidade de desenvolvimento ofertadas, todas em escala Likert de cinco pontos. A amostra foi composta por 122 estudantes e as análises realizadas com o auxílio dos softwares Excel e R. Entre os resultados obtidos destacam-se o atendimento e clareza das informações oferecidas pelos funcionários da biblioteca $(4,082)$, o compromisso da instituição com a qualidade de formação $(4,041)$ e relacionamento com os professores $(4,041)$ com maior grau de satisfação, em contra partida a satisfação com a velocidade da internet $(2,164)$ e diversidade das atividades extracurriculares oferecidas pela instituição $(3,000)$ tiveram baixos índices de satisfação. A confiabilidade do questionário foi verificada através do coeficiente Alpha de Cronbach. Espera-se que este trabalho sirva como um instrumento de difusão das opiniões dos discentes do Campus e auxilie na avaliação da eficácia institucional no âmbito educacional.
\end{abstract}

Palavras-Chave: Satisfação. Engenharia Civil. Estudantes.

\section{SCALE OF SATISFACTION WITH ACADEMIC EXPERIENCE OF STUDENTS OF IFMG- CAMPUS PIUMHI}

\begin{abstract}
This paper aims to analyze the degree of satisfaction of the students of Bachelor of Civil Engineering course at Federal Institute of Minas Gerais (IFMG) - Piumhi Advanced Campus. This analytical-descriptive study was developed with qualitative data, raised through a questionnaire composed by 20 questions selected from the Academic Experience Satisfaction Scale (ESEA). These questions were about the campus (7 questions), the Civil Engineering course (6 questions), and the opportunities on development that are offered (7 questions), all in five-point Likert scale. The sample consisted of 122 students and the analyzes were performed

\footnotetext{
${ }^{1}$ Como citar este artigo:

COSTA, H. R. S. et al. Escala de satisfação com a experiência acadêmica dos estudantes do IFMG - Campus Piumhi. ForScience, Formiga, v. 8, n. 2, e00734, jul./dez. 2020. DOI: 10.29069/forscience.2020v8n2.e734.
}

\footnotetext{
${ }^{2}$ Autor para correspondência: Higor Rodrigues Silva Costa, e-mail: higorcosta882@gmail.com
} 
with the software Excel. Among the results obtained are: attendance and clarity of information provided by library staff $(4,082)$; the institution's commitment to the quality of the professional qualification $(4,041)$, and the relationship with the teachers $(4,041)$ with the highest degree of satisfaction. In contrast, the Internet speed $(2,164)$ and the diversity of extracurricular activities offered by the institution $(3,000)$ can be highlighted because of the low degree of satisfaction. The reliability of the questionnaire was verified using the Cronbach Alpha coefficient. It is hoped that this paper will serve as an instrument for disseminating the opinions from the campus students, and as evaluation for the institutional effectiveness in the educational scope.

Keywords: Satisfaction. Civil Engineering. Students.

\section{INTRODUÇÃO}

As Instituições Federais de Ensino Superior (IFES) atualmente desenvolvem um papel importante no que se diz respeito não apenas na formação acadêmica de seus alunos, mas também no âmbito de formação humana e social.

Segundo Figurelli (2001), estas Instituições têm adotado gradativamente uma postura em que a qualidade e a pertinência dos serviços ofertados passam a ser cada vez mais instrumentos de avaliação cotidiana, apontando para a importância de levantamentos rotineiros que as mensuram. Dessa forma, é essencial descobrir se na visão dos estudantes essas Instituições estão no caminho certo em busca da excelência.

$\mathrm{Na}$ literatura, é comum encontrar trabalhos que buscam avaliar a satisfação dos estudantes. Como exemplo, Carmo et al. (2012) analisam esta temática para estudantes da Faculdade de Estudos Sociais da Universidade Federal do Amazonas. Migot (2015) avalia o nível de satisfação dos acadêmicos sob a perspectiva de incentivo e direcionamento da Universidade em relação ao curso escolhido, enquanto que no trabalho de Ferreira, Santos e Costa (2016) é feita uma avaliação da satisfação de formandos de um curso de graduação em Administração de uma faculdade pública paulista. Já Tomio, Souza e Maia (2007) têm por finalidade avaliar a satisfação dos estudantes de Administração com o curso e sua relação com a imagem da Instituição de Ensino Superior.

Nesta perspectiva, este artigo tem o objetivo de propor uma investigação acerca do grau de satisfação dos estudantes do curso de Bacharelado em Engenharia Civil do Instituto Federal de Educação, Ciência e Tecnologia de Minas Gerais (IFMG) - Campus Avançado Piumhi, utilizando alguns itens da Escala de Satisfação com a Experiência Acadêmica (ESEA), como referência. O curso possui carga horária total de 3600 horas, distribuídas entre disciplinas obrigatórias, aulas práticas, estágios e atividades complementares e, até o segundo semestre de 2018 contava com 173 matrículas regulares. 


\section{MATERIAL E MÉTODOS}

Este estudo, de caráter qualitativo, foi desenvolvido no segundo semestre de 2018, a partir de uma atividade proposta na Disciplina de "Estatística e Probabilidade", ofertada no quarto semestre do Curso, em que se propôs uma pesquisa de campo com características analítico-descritivas, envolvendo os conceitos estatísticos trabalhados no curso.

Participaram dessa pesquisa, 122 estudantes do curso Bacharelado em Engenharia Civil do IFMG - Campus Avançado Piumhi, selecionados por um processo de amostragem aleatória simples. O cálculo do tamanho da amostra se deu de acordo com equação proposta por Bolfarine e Bussab (2005), adotando 95\% de nível de confiança e 2\% de erro máximo. A coleta de dados se fez no segundo semestre de 2018, por meio do envio de um questionário construído com o sistema de Formulários Google (Google Forms), enviado aos estudantes amostrados.

Considerou-se 20 itens da Escala de Satisfação com a Experiência Acadêmica referentes a satisfação com a Instituição (7 itens), satisfação com o curso (6 itens) e oportunidades de desenvolvimento (7 itens). A ESEA é um instrumento de medição de qualidade, composto por 40 itens desenvolvidos por meio de uma escala do tipo Likert de cinco pontos, cuja gradação varia entre os extremos: (1) Nada satisfeito e (5) Totalmente satisfeito. O preenchimento do questionário ocorreu de forma anônima.

As análises descritivas foram realizadas com o auxílio dos softwares Excel e do pacote MASS (VENABLES; RIPLEY, 2002) do software R (R CORE TEAM, 2019), utilizado por ser livre e de código aberto de baixa complexidade. Foram construídas figuras e realizados cálculos de médias e desvios-padrão para resumir as informações obtidas. A confiabilidade do questionário foi mensurada utilizado o coeficiente Alpha de Cronbach, cuja classificação, segundo Hora, Monteiro e Arica (2010), se dá conforme a Tabela 1.

Tabela 1- Classificação da confiabilidade de um questionário de acordo com o Coeficiente Alpha de Cronbach

\begin{tabular}{cclccr}
\hline Confiabilidade & Muito Baixa & Baixa & Moderada & Alta & Muito Alta \\
\hline Valor de $\alpha$ & $\alpha \leq 0,30$ & $0,30<\alpha$ & $0,60<\alpha$ & $0,75<\alpha$ & $\alpha>0,90$ \\
& & $\leq 0,60$ & $\leq 0,75$ & $\leq 0,90$ &
\end{tabular}

Fonte: Autores (2019)

Este coeficiente foi calculado para cada uma das dimensões separadamente e também para o conjunto completo de itens.

\section{RESULTADOS E DISCUSSÃO}


Segundo Lemos (2011) a preocupação com a qualidade de ações educacionais têm impacto indiscutível no sucesso do processo ensino-aprendizagem dos estudantes, considerando que as intervenções pedagógicas passíveis de serem realizadas em ambientes deficitários, podem trazem ganhos significativos.

A Tabela 2 mostra o grau de satisfação médio e o desvio-padrão obtido para cada um dos 20 itens que compuseram o questionário enviado aos estudantes amostrado, separados por dimensão: satisfação com a Instituição, satisfação com o Curso e oportunidade de desenvolvimento.

Tabela 2 - Medidas-resumo calculadas para os itens do questionário

Dimensão Desvio Padrão

Satisfação com a Instituição

Grau de Satisfação 3,604

1) Satisfação com o acervo da biblioteca 0,882 3,820

2) Satisfação com a velocidade da internet 1,160 2,164

3) Equipamentos e softwares oferecidos pelo laboratório de 0,813 3,869 informática

4) Atendimento e clareza das informações oferecidas pelos 0,839 4,082 funcionários da biblioteca

5) Compromisso da instituição com a qualidade de 1,007 4,041 formação

6) Infraestrutura física das salas de aula 0,964 3,500

7) Acessibilidade 0,990 3,754

\section{Satisfação com o Curso}

$\mathbf{3 , 8 2 0}$

8) Interesse dos professores em atender os estudantes

0,886

4,008 durante as aulas

9) Conhecimento dos professores sobre o conteúdo das disciplinas que ministram

10) Disponibilidade dos professores em atender os alunos fora da sala de aula

11) Estratégia de aula utilizada pelos professores 0,902

12) Adequação do conteúdo para formação

0,971

13) Relacionamento com os professores

0,847 
14) Programas ou serviços de apoio aos estudantes 1,053

oferecidos pela instituição

15) Programa de apoio financeiro oferecido pela instituição

16) Oportunidade de desenvolvimento pessoal oferecida pela instituição

17) Diversidade das atividades extracurriculares oferecidas pela instituição

18) Oportunidade de desenvolver projetos de pesquisa

19) Oportunidade de desenvolver projetos de ensino

20) Oportunidade de desenvolver projetos de extensão

1,049

Observou-se que todas as dimensões analisadas, considerando uma análise conjunta, obtiveram bons índices, com destaque para a dimensão satisfação com o Curso, cujo valor médio calculado foi de 3,820. A dimensão com menor média estava relacionada com as oportunidades de desenvolvimento, o que pode se justificar pelo fato do Campus ser Avançado, o que traz consideráveis restrições orçamentárias.

A Tabela 3 traz uma estimativa para o coeficiente Alpha de Cronbach calculado para cada dimensão e para o questionário como um todo.

Tabela 3 - Coeficiente Alpha de Cronbach estimado

\begin{tabular}{ccc}
\hline Dimensão & Alpha de Cronbach & Classificação \\
\hline Satisfação com a Instituição & 0,92 & Muito Alta \\
Satisfação com o Curso & 0,91 & Muito Alta \\
Oportunidade de Desenvolvimento & 0,94 & Muito Alta \\
Questionário Completo & 0,87 & Alta \\
\hline
\end{tabular}

Fonte: Autores (2019).

A análise do coeficiente Alpha de Cronbach demostra altos índices de confiabilidade do questionário enquanto instrumento de mensuração do grau de satisfação dos estudantes. A seguir, traremos os resultados obtidos para cada item do questionário, separados por dimensão.

\subsection{Satisfação com a Instituição}

Como dito por Ferreira, Santos e Costa (2016), a avaliação da satisfação dos serviços é um dos principais pontos para a melhoria contínua das organizações. A partir do levantamento 
das percepções e experiências vividas pelos usuários, é possível absorver informações significativas que poderão nortear decisões de planejamento para incrementar a qualidade oferecida pelo serviço. A partir dessa premissa foram discussões sobre a satisfação com a Instituição.

As Figuras 1 e 2 referem-se, respectivamente, à satisfação com a biblioteca e com a satisfação com a velocidade da internet do Campus.

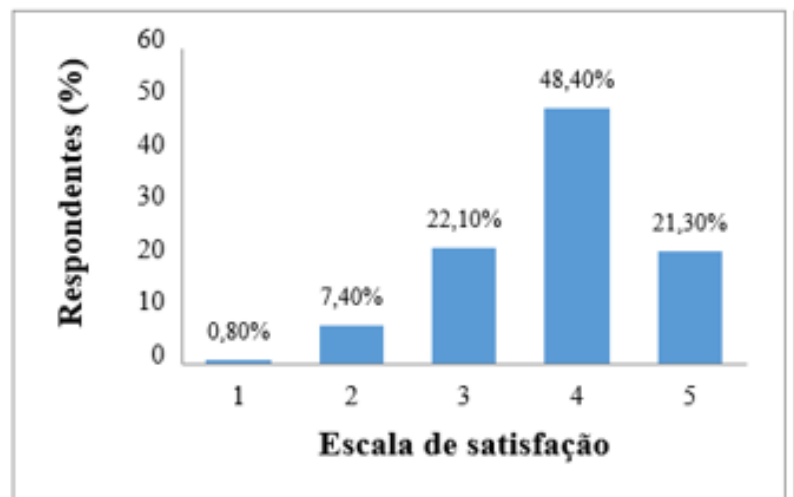

Figura 1- Satisfação com o acervo da biblioteca Fonte: Autores (2019).

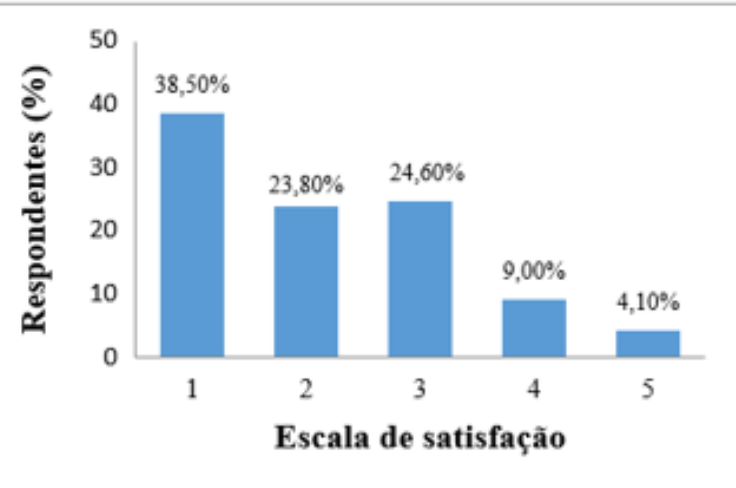

Figura 2 - Satisfação com a velocidade da internet Fonte: Autores (2019).

Os resultados apontam para uma avaliação positiva do acervo da biblioteca, mostra que a mesma tem um acervo bem variado e consegue atender a demanda bibliográfica prosposta nas disciplinas. No entanto, a Figura 2 indica possíveis problemas referentes a velocidade da internet no Campus. Após os resultados obtidos, foram realizados testes para verificar a velocidade da internet e averiguar se essa velocidade era coerente com o números de pessoas que fazem o uso da mesma. Com isso, constatou-se que essa grande insatisfação se dá devido a velocide da internet ser baixa, e não conseguir atender necessidade de todos os usuários, visto que muitos alunos são exclusivamente dependentes da internet do Campus.

As Figuras 3 e 4 referem-se, respectivamente, aos equipamentos e softwares oferecidos pelo laboratório de informática e ao atendimento e clareza das informações oferecidas pelos funcionários da biblioteca. 


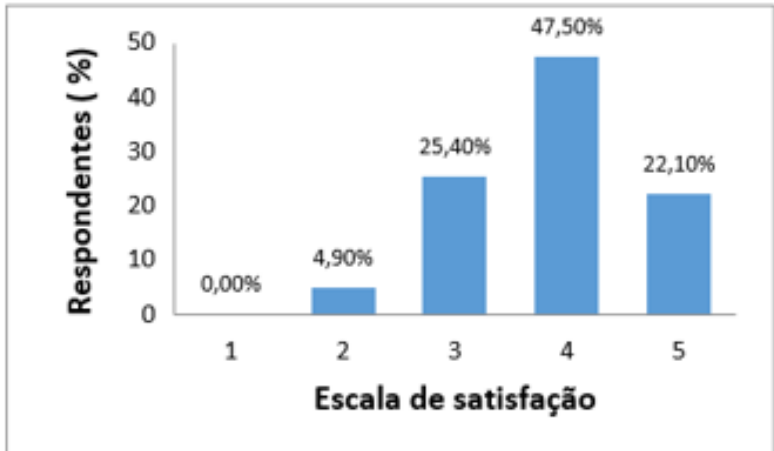

Figura 3 - Equipamentos do laboratório de informática Fonte: Autores (2019).

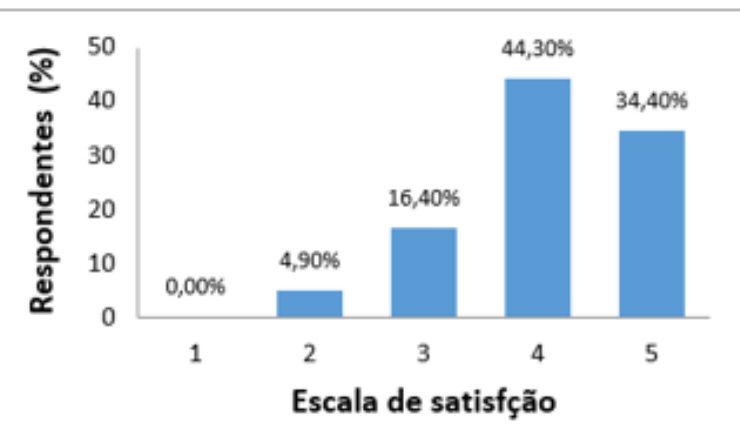

Figura 4 - Funcionários da biblioteca Fonte: Autores (2019).

Nos últimos anos o Campus tem se dedicado à compra de materiais e softwares especializados e já é possível observar o impacto desta medida na opinião dos estudantes envolvidos. Entretanto, acredita-se que há espaço e necessidade de melhorias. Quanto à avaliação dos funcionários da biblioteca, percebe-se o retorno do comprometimento e dedicação dos envolvidos.

As Figuras 5 e 6 referem-se ao compromisso da Instituição com a qualidade de formação e a infraestrutura física das salas de aula, respectivamente e a Figura 7 traz informações acerca da acessibilidade.

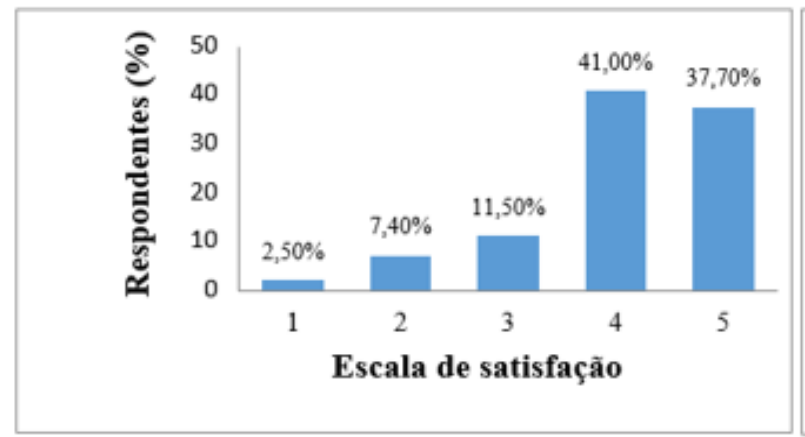

Figura 5 - Compromisso com a qualidade Fonte: Autores (2019).

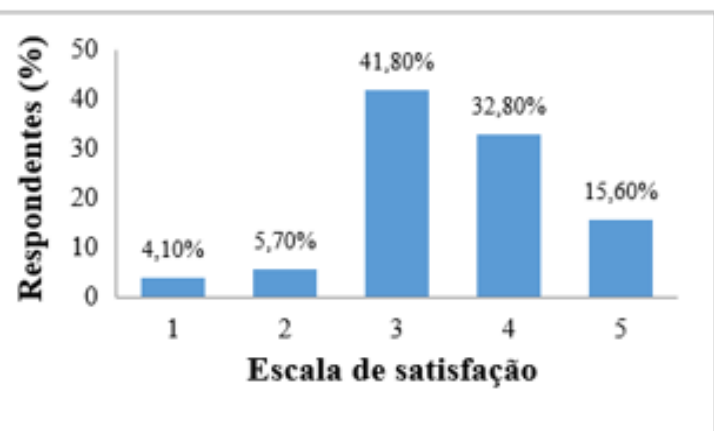

Figura 6 - Infraestrutura física das salas de aula Fonte: Autores (2019).

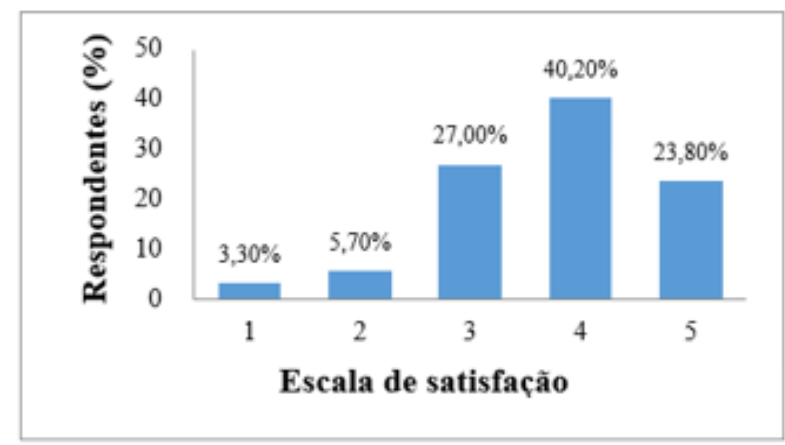

Figura 7 - Acessibilidade Fonte: Autores (2019). 
Aqui, percebeu-se que há um reconhecimento dos estudantes quanto ao compromisso da instituição com a qualidade de formação. Entretanto, percebe-se que a infraestrutura física das salas de aula e a acessibilidade são pontos que merecem uma maior discussão.

\subsection{Satisfação com o Curso}

Para Tomio, Souza e Maia (2007), a realização de pesquisas sobre a satisfação dos alunos, se tornou necessária de vez que a satisfação influencia a imagem corporativa, a qual se constitui em estratégia fundamental de competitividade para a instituição, permitindo a atração de novos estudantes, e fortalecendo a permanência dos já existentes.

As Figuras 8 e 9 referem-se ao interesse dos professores em atender os estudantes durante as aulas e ao conhecimento que eles possuem acerca dos conteúdos das disciplinas que ministram, respectivamente.

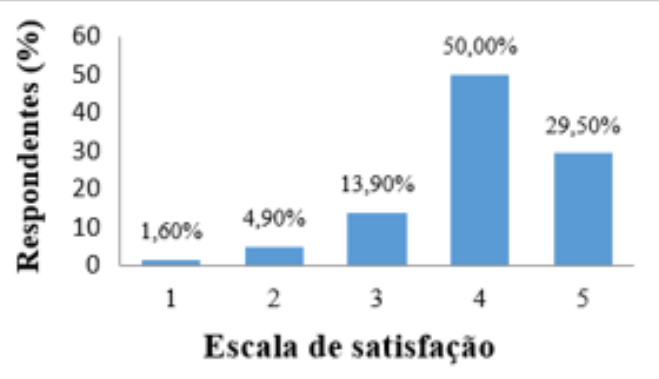

Figura 8 - Interesse dos professores Fonte: Autores (2019).

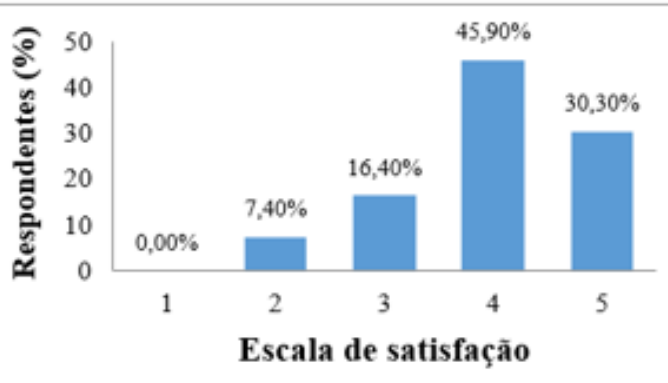

Figura 9 - Conhecimento dos professores Fonte: Autores (2019).

Observou-se que cerca de $80 \%$ dos respondentes estão satisfeitos ou muito satisfeitos com o interesse dos professores em atendê-los. Além disso, mais do que três quartos do total de pesquisados aprovam o grau de conhecimento dos professores.

Pelas Figuras, pode-se inferir que os professores demonstraram interesse em ensinar e tirar dúvidas dos alunos durante as aulas, e estes estão sempre buscando aperfeiçoar seus conhecidos, sobre as disciplinas que ministram.

As Figuras 10 e 11 trazem informações acerca da disponibilidade dos professores em atender os alunos fora da sala de aula e de estratégias utilizadas por eles em suas aulas, respectivamente. 


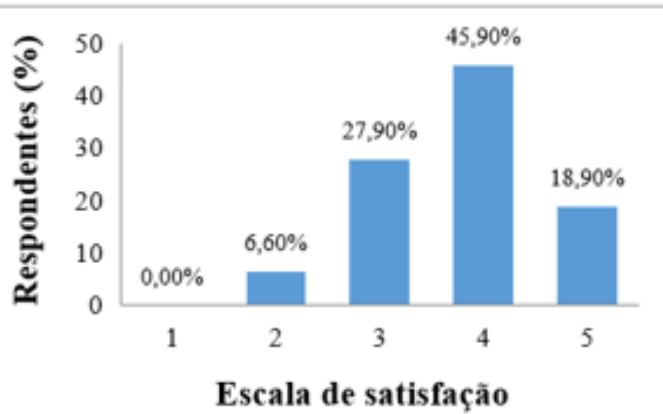

Figura 10 - Disponibilidade dos professores Fonte: Autores (2019).

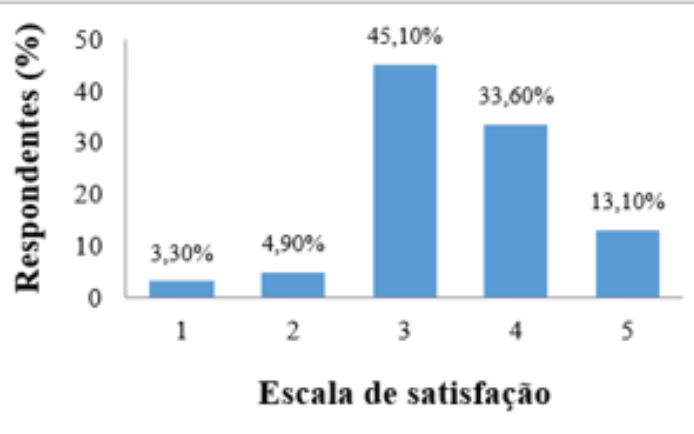

Figura 11: Estratégia de aula utilizada pelos professores Fonte: Autores (2019).

A disponibilidade dos professores é um ponto que merece atenção. Em Campus como este, do tipo avançado, há um limite de 20 docentes que devem se comprometer, não apenas com o ofício de ensinar, mas também o de gerir por meio de representações em comissões, como fiscais de contrato, coordenações de Curso, direções, entre outras, o que pode acarretar uma sobrecarga destes profissionais. Quanto às estratégias de aula, o setor pedagógico tem ofertado oficinas e minicursos que discutem novas metodologias de ensino e acredita-se que haverá um avanço no grau de satisfação deste quesito, nos próximos anos, oriundos desse processo de atualização e formação continuada dos professores.

As Figuras 12 e 13 trazem informações acerca da adequação do conteúdo para a formação e o relacionamento com os professores, respectivamente.

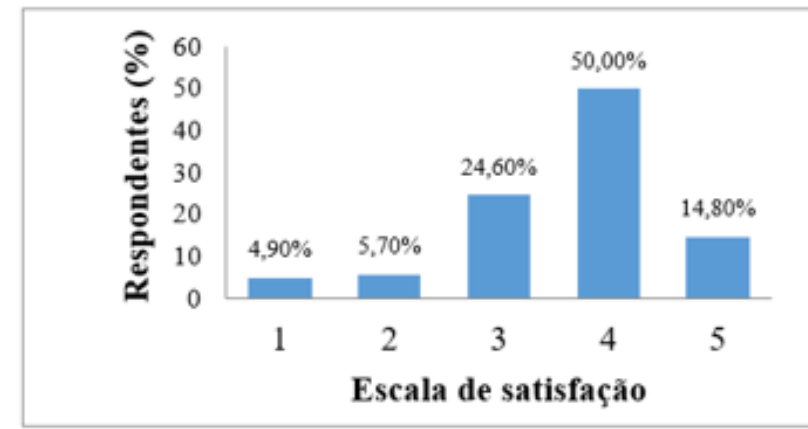

Figura 12 - Adequação do conteúdo para formação Fonte: Autores (2019).

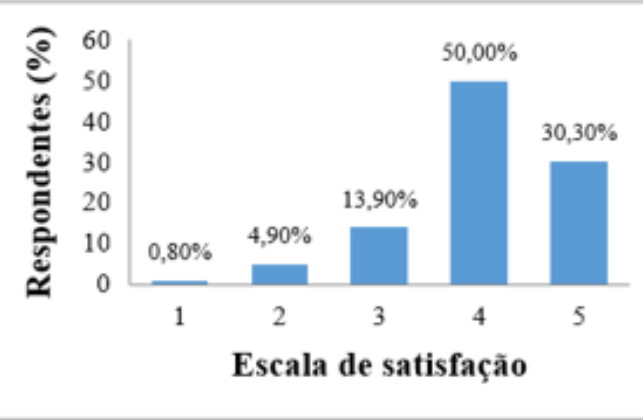

Figuras 13 - Relacionamento com os professores Fonte: Autores (2019).

Em sua maioria os estudantes percebem uma relação entre os conteúdos estudados e a formação. Além disso, mais do que $80 \%$ deles demonstram ter um bom relacionamento com os professores do curso. Esse bom relacionamento pode ser explicado quando se analisa o tamanho do Campus e quantidade de estudantes da instituição, esse fator possibilita maior facilidade de comunicação entre ambos. 


\subsection{Oportunidade de Desenvolvimento}

De acordo com Migot (2015), o objetivo da educação superior são desenvolver aspectos intelectuais e cognitivos dos alunos, formando profissionais capacitados para o mercado de trabalho. Visando esse aspecto, foram analisados as oportunidades de desenvolvimento oferecidas pela instituição.

As Figuras 14 e 15 referem-se a programas ou serviços de apoio aos estudantes oferecidos e a programas de apoio financeiros, respectivamente, oferecidos pela Instituição.

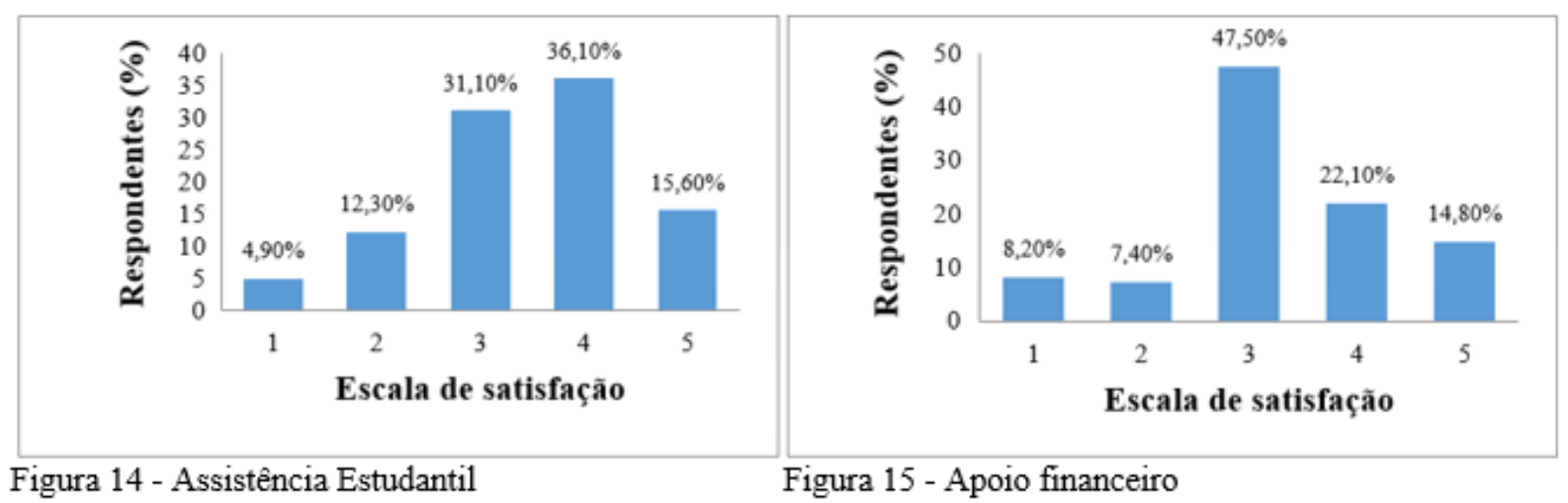

Fonte: Autores (2019). $\quad$ Fonte: Autores (2019).

No que se refere à assistência estudantil, tanto num âmbito geral, quanto no específico do apoio financeiro, percebe-se um grande número de estudantes que trataram o assunto como “indiferente", talvez por não participarem ou conhecerem a fundo as políticas institucionais referentes ao tema. Acredita-se que deva ocorrer maior divulgação acerca do tema, considerando a transparência dos processos de distribuição de bolsas e o acompanhamento de frequências dos estudantes envolvidos.

As Figuras 16 e 17 referem-se, respectivamente, às oportunidades de desenvolvimento pessoal e à diversidade das atividades extracurriculares oferecidas pela Instituição.

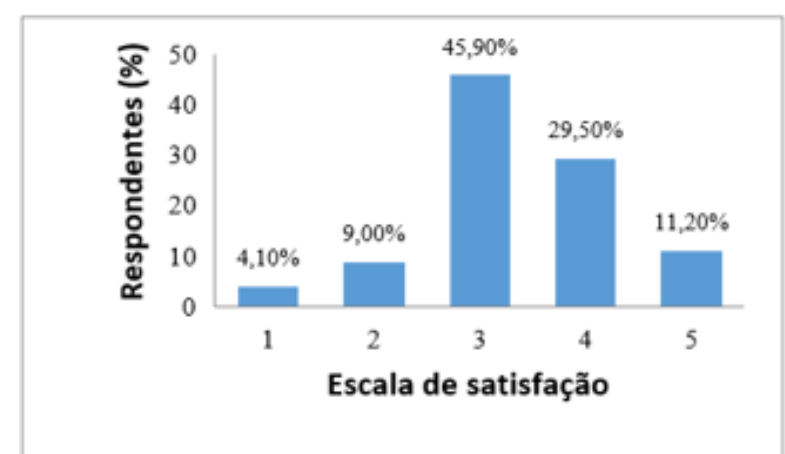

Figura 16 - Desenvolvimento pessoal: oportunidades Fonte: Autores (2019).

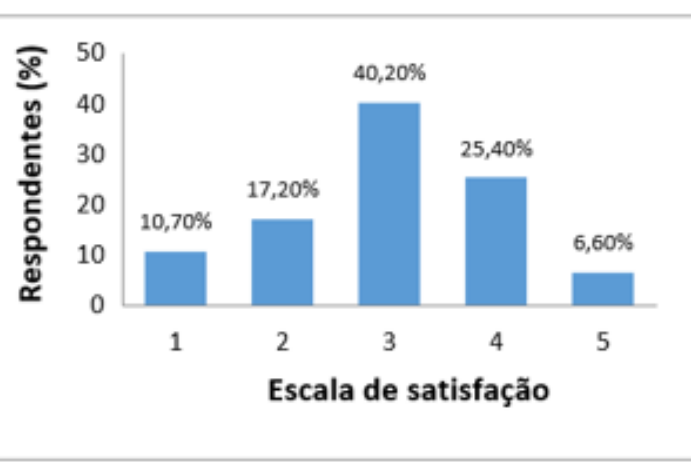

Figura 17 - Atividades extracurriculares Fonte: Autores (2019). 
Apenas cerca de $30 \%$ dos respondentes demonstraram estarem satisfeitos com as oportunidades oferecidas pelo Campus no âmbito do desenvolvimento pessoal. Esses dados mostram que as oportunidades de desenvolvimento pessoal são existentes, porém, pode-se entender que estas não são muio difundidas no Campus devido grande parte dos entrevistados se mostrarem inferentes a isto. Além disso, percebe-se a necessidade da oferta de atividades extracurriculares. Ressalta-se que, atualmente, os estudantes precisam cumprir 90 horas de atividades complementares para obtenção do título acadêmico.

As Figuras 18 e 19 apresentam, respectivamente, as opiniões dos estudantes quanto as oportunidades de desenvolver projetos de pesquisa e projetos de ensino. A Figura 20 se refere às oportunidades de desenvolvimento de projetos de extensão.

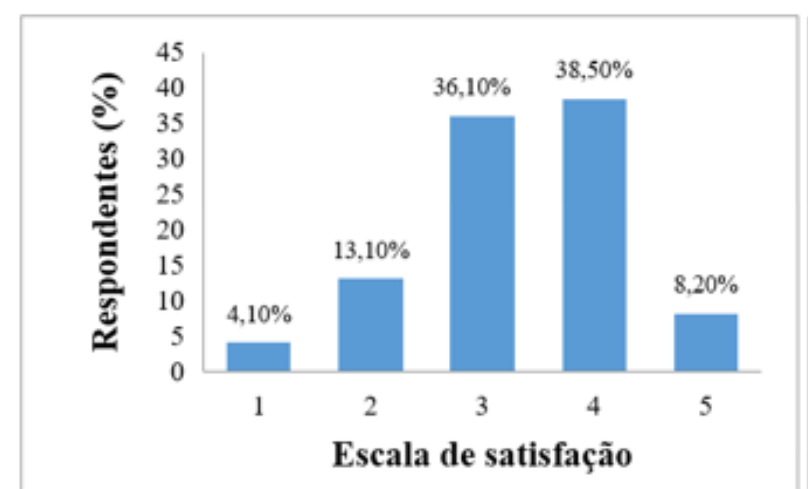

Figura 18 - Projetos de pesquisa Fonte: Autores (2019).

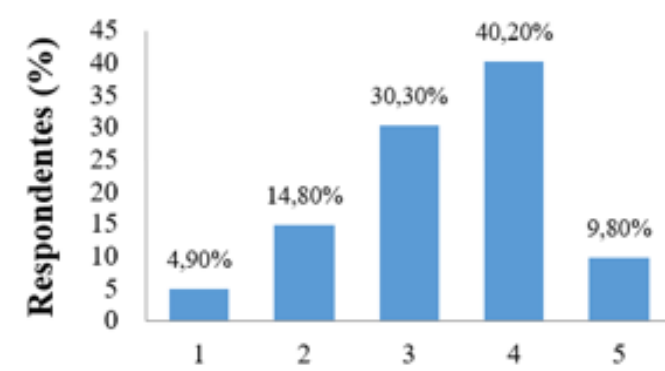

Escala de satisfação
Figura 19 - Projetos de ensino Fonte: Os autores (2019).

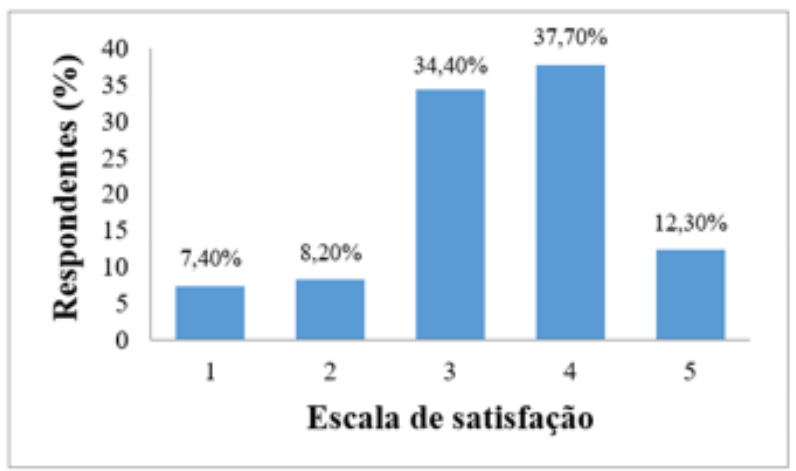

Figura 20 - Projetos de extensão Fonte: Os autores (2019).

O tripé considerado base da estrutura dos Institutos Federais é composto pelo ensino, pesquisa e extensão. Oportunidades nessas áreas são bastante significativas para a formação humana, social e profissional do estudante. As Figuras mostram que uma parcela significativa dos estudantes se revelaram indiferentes quanto a esses temas. Estas respostas obtidas pelo questionário avaliado demonstraram que a Instituição precisa melhorar neste quesito. 


\section{CONCLUSÃO}

Neste trabalho, procurou-se realizar um levantamento a respeito do grau de satisfação dos estudantes do Curso Bacharelado em Engenharia Civil do IFMG - Campus Avançado Piumhi.

Embora seja de caráter inicial e descritivo, acredita-se que este tipo de pesquisa é de fundamental importância para um bom desenvolvimento de todos os setores do Campus, considerando que o estudante que não se encontra satisfeito, está propício à retenção e a evasão no curso, problemas seriamente enfrentados pela maioria dos cursos de graduação no país.

Espera-se que este trabalho sirva como um instrumento de difusão da opinião dos estudantes e auxilie na melhoria dos processos gerenciais do Campus, mediante ações que podem ser propostas após a análise dos resultados aqui demonstrados e discutidos.

\section{REFERÊNCIAS}

BOLFARINE, H.; BUSSAB, W. O. Elementos de amostragem. São Paulo: Editora Blucher, 2005.

CARMO, Y. A et al. Análise de satisfação dos alunos da faculdade de estudos sociais da Universidade Federal do Amazonas. 2012. Disponível em: http://www.convibra.com.br/upload/paper/2012/31/2012_31_4968.pdf. Acesso em: 25 out. 2018.

FERREIRA, L. M.; SANTOS, V. M.; COSTA, A. L. Avaliação de satisfação de formando de um curso de graduação em Administração de uma faculdade pública paulista. 2016. Disponível em: http://www.revistas.usp.br/gradmais/article/view/123114/119486. Acesso em: 16 out. 2018.

FIGURELLI, J. C. R. Qualidade em instituição de ensino superior: um estudo de caso avaliando as percepções dos públicos envolvidos. 2001. Dissertação (Mestrado em Engenharia de Produção) - Universidade Federal do Rio Grande do Sul, Porto Alegre, 2001. Disponível em: https://lume.ufrgs.br/handle/10183/2387. Acesso em: 16 out. 2018.

HORA, H. R. M.; MONTEIRO, G. T. R.; ARICA, J. Confiabilidade em questionários para qualidade: um estudo com o Coeficiente Alfa de Cronbach. Produto \& Produção, Porto Alegre, v. 11, n. 2, p. 85-103, 2010.

LEMOS, M. I. S. Análise da satisfação de estudantes num curso em e-learning no ensino superior. 2011. Dissertação (Área de Especialização em Tecnologias de Informação e Comunicação e Educação) - Instituto De Educação Da Universidade De Lisboa, Lisboa, 2011. Disponível em: http://repositorio.ul.pt/bitstream/10451/4413/1/ulfpie039557_tm.pdf. Acesso em: 22 out. 2018. 
MIGOT, S. E. Nível de satisfação dos acadêmicos de uma universidade sob a perspectiva de incentivo e direcionamento da universidade em relação ao curso escolhido. 2015.

Disponível em: http://www.gestaouniversitaria.com.br/artigos/nivel-de-satisfacao-dosacademicos-de-uma-universidade-sob-a-perspectiva-de-incentivo-e-direcionamento-dauniversidade-em-relacao-ao-curso-escolhido. Acesso em: 16 out. 2018.

R Core Team. 2019. R: A Language and environment for statistical computing. Vienna, Austria: R Foundation for Statistical Computing. Disponível em: www.R-project.org/. Acesso em: 19 out. 2018.

TOMIO, J. L.; SOUZA, M. J. B.; MAIA, F. B. A. Satisfação dos alunos de administração com o curso e sua relação com a imagem da instituição de ensino superior. 2007. Disponível em: http://www.anpad.org.br/admin/pdf/ENEPQ307.pdf. Acesso em: 19 out. 2018.

VENABLES, W. N.; RIPLEY, B. D. Modern applied statistics with S. New York: Springer.Fourth Edition, 2002.

\section{DADOS DOS AUTORES}

\section{Higor Rodriges Silva Costa}

E-mail: higorcosta882@gmail.com

Currículo Lattes: http://lattes.cnpq.br/3693944338904317

Graduando em Engenharia Civil pelo Instituto Federal de Educação, Ciência e Tecnologia de Minas Gerais (IFMG) Campus Piumhi.

\section{Pedro Henrique da Costa}

E-mail: pedropta474@gmail.com

Currículo Lattes: http://lattes.cnpq.br/4821555785585141

Graduando em Engenharia Civil pelo Instituto Federal de Educação, Ciência e Tecnologia de Minas Gerais (IFMG) Campus Piumhi.

\section{Tales Junio Costa Chaves}

E-mail: talesjrchavespta@gmail.com

Currículo Lattes: http://lattes.cnpq.br/9522438749097843

Graduando em Engenharia Civil pelo Instituto Federal de Educação, Ciência e Tecnologia de Minas Gerais (IFMG) Campus Piumhi.

\section{Denilson Junio Marques Soares}

E-mail: denilson.marques@ifmg.edu.br

Currículo Lattes: http://lattes.cnpq.br/1813099481556666

Doutorando do Programa de Pós-Graduação em Educação (PPGE) da Universidade Federal do Espírito Santo (UFES). Mestre em Estatística Aplicada e Biometria e Licenciado em Matemática pela Universidade Federal de Viçosa (UFV). Professor do Instituto Federal de Minas Gerais (IFMG) Campus Piumhi. 